Original Research Article

\title{
A comparative study of efficacy and safety of glucosamine plus chondroitin sulphate versus rosehip as add on therapy to NSAIDs in patients suffering from osteoarthritis
}

\author{
Kiranpreet Kaur ${ }^{1}$, Anjleen Kaur ${ }^{1 *}$, Prabhsimran Singh ${ }^{2}$, Amandeep Singh Bakshi ${ }^{2}$
}

\begin{abstract}
${ }^{1}$ Department of Pharmacology, ${ }^{2}$ Department of Orthopedics, Govt. Medical College, Patiala, Punjab, India
\end{abstract}

\section{Received: 15 September 2018 \\ Revised: 03 October 2018 \\ Accepted: 10 October 2018 \\ *Correspondence to: \\ Dr. Anjleen Kaur, \\ Email: drkiranpreetmalhotra@ ymail.com}

Copyright: (C) the author(s), publisher and licensee Medip Academy. This is an openaccess article distributed under the terms of the Creative Commons Attribution NonCommercial License, which permits unrestricted noncommercial use, distribution, and reproduction in any medium, provided the original work is properly cited.

\begin{abstract}
Background: Osteoarthritis is a chronic and debilitating disease. Management of disease is a big challenge. NSAIDS play an important role but have many adverse reactions. So, this study was designed to evaluate the efficacy and safety of natural compound rosehip versus glucosamine and chondroitin sulphate in patients of osteoarthritis.

Methods: An open label, randomized, parallel group comparative study, conducted on patients of either sex with confirmed diagnosis of osteoarthritis on standard NSAIDs therapy, attending the outpatient department of orthopedics in a tertiary care centre. 150 patients were enrolled and divided into three groups (group A, group B and group C) of 50 each. Patients of group A were given Glucosamine plus chondroitin sulphate for 12 weeks. Group B was given rosehip for 12 weeks and group $\mathrm{C}$ placebo. These supplements were given as add on therapy. Patients were monitored and adverse drug reactions were noted. The data was analysed statistically using t- test for efficacy and descriptive stats for assessing the safety.

Results: Efficacy was assessed by comparing mean reduction in the pain intensity between group A and B, group B gives highly significant results as compared to group A. While comparing joint tenderness, swelling around joint, mean functional capacity and improvement in the overall assessment, group B gives significant results as compared to group A. It was also observed that group $\mathrm{A}$ and group $\mathrm{B}$ were better than group $\mathrm{C}$ in all the efficacy parameters. All the drugs were well tolerated and systemically safe.

Conclusions: There was significant difference in efficacy of rosehip compared with glaucosamine and chondroitin sulphate in patients of osteoarthritis. In comparison there was no significant difference in safety of two drugs and both were considered safe in patients.
\end{abstract}

Keywords: Glucosamine and chondroitin sulphate, Osteoarthritis, Rosehip

\section{INTRODUCTION}

Osteoarthritis is a chronic and debilitating disease. ${ }^{1}$ Osteoarthritis (OA) is a common degenerative disease in older adults that is characterized by joint pain and dysfunction due to progressive subchondral bone damage, articular cartilage loss, inflammation/synovitis, and osteophyte formation. ${ }^{2}$ Patient clinically presents with symptoms like pain or stiffness of joint. Swelling is late manifestation of disease. Gross limitation of movement and development of deformity occurs late as a result of capsular contracture and incongruity of articular surfaces. Management includes mostly symptomatic relief i.e. reduction in pain and improvement of joint function. ${ }^{3}$

NSAIDS play very important role in the management of osteoarthritis. ${ }^{3}$ Natural compounds are used as add on therapy in the treatment of osteoarthritis. Natural compounds like glucosamine and chondroitin sulphate are slow acting drugs for osteoarthritis. It slows deterioration 
of cartilage relieves pain and improve joint stability. They increase collagen and proteoglycan synthesis in human articular chondrocytes and are able to reduce the production of some pro-inflammatory mediators and proteases, to reduce the cellular death process and improve the anabolic / catabolic balance of extracellular cartilage matrix. ${ }^{4}$

Rosehip is a unique dietary supplement which is used traditionally to treat a range of conditions including diarrhea, bladder infections and diabetes. Antiinflammatory action of rosehip has been attributed to high quantities of galactolipids, a class of compounds recently shown to possess antitumor promoting and antiinflammatory activity. ${ }^{5}$ Other Rosehip constituents such as ascorbic acid, polyphenols, flavonoids, and unsaturated fatty acids might contribute to alleviate OA mainly via their anti-inflammatory properties. ${ }^{6}$ As these natural compounds decreases the progression of disease and prevent early onset of complication. They also decrease the intake of NSAIDs for pain reduction and NSAIDs related ADRs. The purpose of present study is to compare the efficacy and safety of glucosamine and chondroitin sulphate versus rosehip as add on therapy to NSAIDS in patients suffering from osteoarthritis.

\section{METHODS}

An open, randomized, parallel group study was conducted after obtaining written informed consent from the patients. The study was done in accordance with the principles laid in the declaration of Helsinki and was approved by Institutional ethics committee. ${ }^{7}$ Patients included in the study were males and females between 35-65yrs with confirmed diagnosis of osteoarthritis on NSAID therapy. Patients with known hypersensitivity, major surgery, significant renal, hepatic, hematological or cardiovascular disease, with other types of inflammatory arthritis like rheumatoid arthritis, gout, drug abuse, with history of skin disorders precipitated or aggravated by drugs and pregnant and nursing mothers were excluded from the study.

\section{Study protocol}

A total of 150 patients were enrolled and divided into three groups (group A, group B and group C) of 50 each. Patients of group A were given glucosamine plus chondroitin sulphate for 12 weeks. Patients of group B were given Rosehip for 12 weeks and group $\mathrm{C}$ was given placebo for 12 weeks. The standard treatment of OA was continued in all the three groups as prescribed by the orthopedician. Patients were given NSAIDs as a standard therapy to relieve pain. These natural supplements were given as add on therapy. Among NSAID acelofenac plus paracetamol combination was given to the patients to see the effects of add on therapy. The study was done from February to November 2017.

Patients were assessed at visit 0 i.e. 0 week (baseline visit) then visit 1 (after 4 weeks), visit 2 (after 8 weeks) and visit
3 (after 12 weeks) for all the efficacy parameters. Data was collected on patient's demographic characteristics, functional status involving different parameters like pain intensity, joint tenderness, swelling, erythema, pain on movement, functional capacity and overall assessment. pain intensity (i.e. spontaneous pain) on VAS, pain on movement and Functional capacity on Likert scale. To evaluate joint tenderness, swelling, erythema Likert scale was used, and patient's overall arthritic condition was rated on a five point scale. ${ }^{8}$ All the adverse events in each treatment group were noted at the follow up visits, as reported by patients.

\section{Statistical analysis}

Data was statistically analysed using student's 't' test. ${ }^{9}$ For adverse drug reaction evaluation descriptive statistics was used. A difference between the treated and control group which would have arisen by chance is ' $p$ ' value. If it is less than 0.05 , it is considered significant $(S)$, ' $p$ ' value less than 0.001 is considered highly significant (HS). If it is more than 0.05 , it is considered non-significant (NS).

\section{RESULTS}

A total of 150 patients were enrolled and divided into three groups (group A, group B and group C) of 50 each. All groups of patients were comparable with baseline characteristics with respect to age, sex and weight (Table 1). With respect to gender distribution there is a preponderance of female patients in all the groups. Table 2 shows that there was no significant difference between the three groups as far as distribution of osteoarthritis in the right knee, left knee or both and the duration of disease.

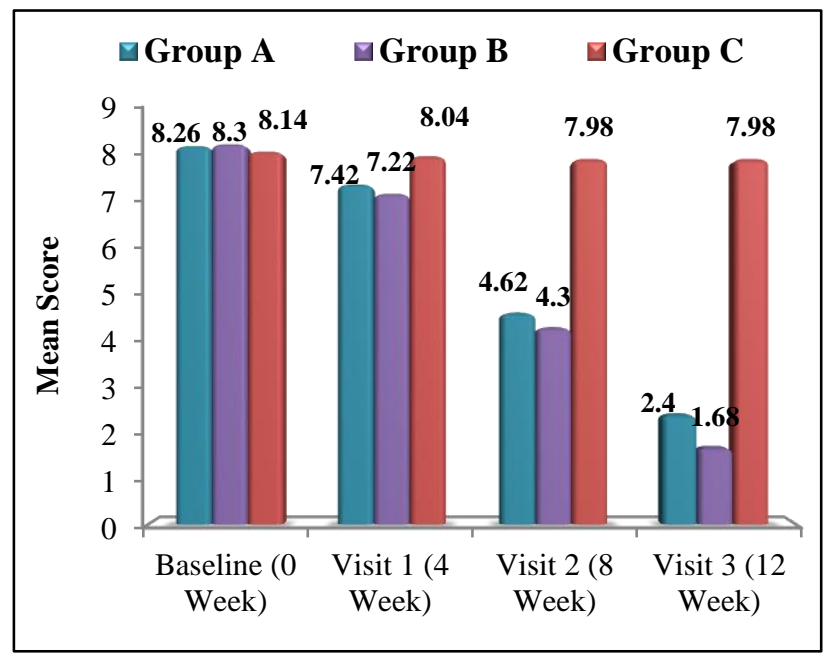

Figure 1: Comparison of mean pain intensity scores between group $A$, group $B$, and group $C$ at different visits.

Figure 1 shows comparison of reduction in mean pain intensity between group $\mathrm{A}$, group $\mathrm{B}$, and group $\mathrm{C}$ at different visits. By taking inter-group comparison, it was observed that at visit 1 and visit 2 there was no significant 
difference between group A and group B as far as intensity of pain is concerned but at visit 3 there was highly significant difference between the group A and group B. In comparison there was highly significant difference between group A and group C and group B and group C at all the visits.

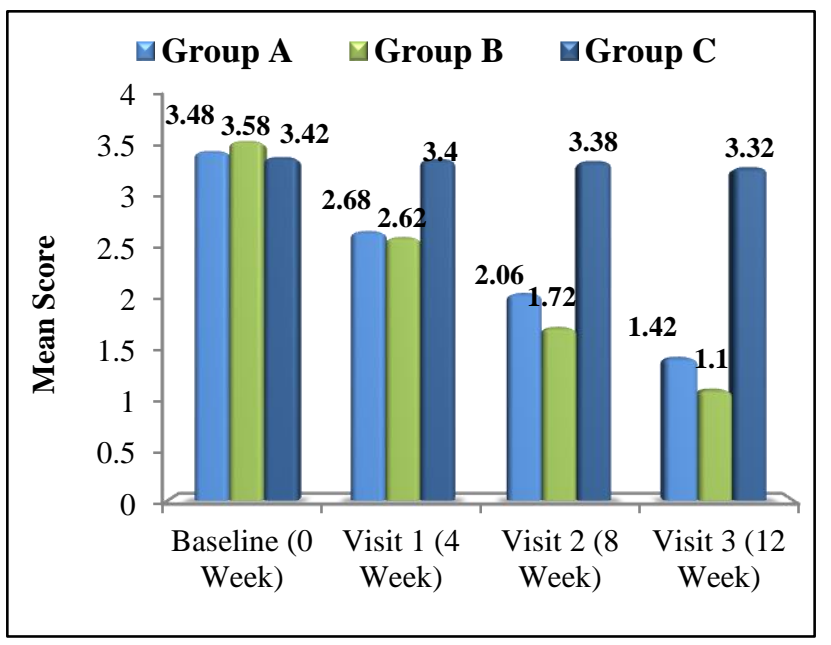

Figure 2: Comparison of mean joint tenderness scores between group $\mathrm{A}$, group $\mathrm{B}$, And group $\mathrm{C}$ at different visits.

Figure 2 shows comparison of reduction in joint tenderness between group A, group B and group C at different visits. By taking inter -group comparison, it was observed that at visit 1 and visit 2 there was no significant difference between group A and group B at 4 weeks but at 8 weeks and 12 weeks there was significant difference in reduction of joint tenderness between two groups. While in comparison there was highly significant difference between group $\mathrm{A}$ and $\mathrm{C}$ and Group $\mathrm{B}$ and $\mathrm{C}$ at all visits. Similarly, if authors' compare mean swelling of joint scores between group A, group B, and group C at different visits. It was observed that there was no significant difference at visit 1and 2 between group A and group B while at visit 3 (12 weeks) there was significant difference in reduction in swelling of joint between group $\mathrm{A}$ and group B. In comparison to this it was observed that there was highly significant difference between group A and C and between group $\mathrm{B}$ and $\mathrm{C}$.

Figure 3 shows comparison of mean erythema scores between group A, group B, and group C at different Visits. By taking inter group comparison, it was observed that there was no significant difference at all the 3 visits as $p$ value $>0.05$ between group A and group B. In comparison to this it was observed that there was highly significant difference between group $\mathrm{A}$ and $\mathrm{C}$ and group $\mathrm{B}$ and $\mathrm{C}$ at all 3 visits as $\mathrm{p}$ value $<0.01$.

Similar results were observed on comparison of mean pain on movement score between all 3 groups at different visits. By taking inter group comparison; it was observed that there was no significant difference at all the 3 visits between group A and group B. In comparison to this it was observed that there was highly significant difference between group $\mathrm{A}$ and $\mathrm{C}$ and group $\mathrm{B}$ and $\mathrm{C}$ at all 3 visits as $\mathrm{p}$ value $<0.01$.

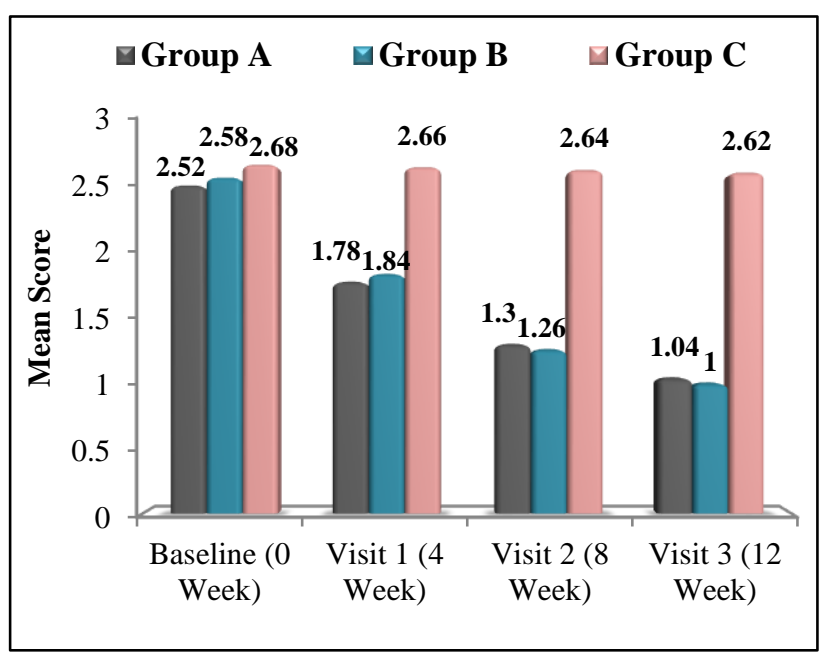

\section{Figure 3: Comparison of mean erythema scores between group $\mathrm{A}$, group $\mathrm{B}$, And group $\mathrm{C}$ at different visits.}

Table 3 shows comparison of mean functional capacity scores between group A, group B, and group $\mathrm{C}$ at different visits. By taking inter group comparison, it was observed that there was no significant difference at visit 1 and 2 but at visit 3 it was observed that there was significant improvement in mean functional capacity between group A and group B. In comparison to this it was observed that there was highly significant difference between group $\mathrm{A}$ and $\mathrm{C}$ and group $\mathrm{B}$ and $\mathrm{C}$ at all 3 visits as $\mathrm{p}$ value $<0.01$.

Table 4 shows comparison of mean overall assessment scores between groups $\mathrm{A}$, group $\mathrm{B}$ and group $\mathrm{C}$ at different visits. By taking inter group comparison, it was observed that there was no significant difference at visit 1 and 2 but at visit 3 it was observed that there was significant improvement in mean overall assessment between group A and group B.

In comparison to this it was observed that there was significant difference at visit 2 but highly significant difference at visit 3 between group $\mathrm{A}$ and $\mathrm{C}$ and highly significant at all visits between group $\mathrm{B}$ and $\mathrm{C}$.

Figure 4 shows comparison of adverse events between group A, group B and group C at all visits. It was observed that in patient taking Glucosamine and chondroitin suphate (group A) that incidence of bloating was $4(8 \%)$, diarrhea was $2(4 \%)$, hair loss 1 (2\%), Nausea was 1 (2\%) was reported. In patients taking Rosehip (group B) that incidence of diarrhea was $4(8 \%)$, heart burn $1(2 \%)$, stomach pain was $2(4 \%)$ was reported. In patients taking placebo (group C) incidence of diarrhea was $1(2 \%)$, heartburn was $1(2 \%)$, stomach pain was $4(8 \%)$, nausea 1 (2\%) was reported. 


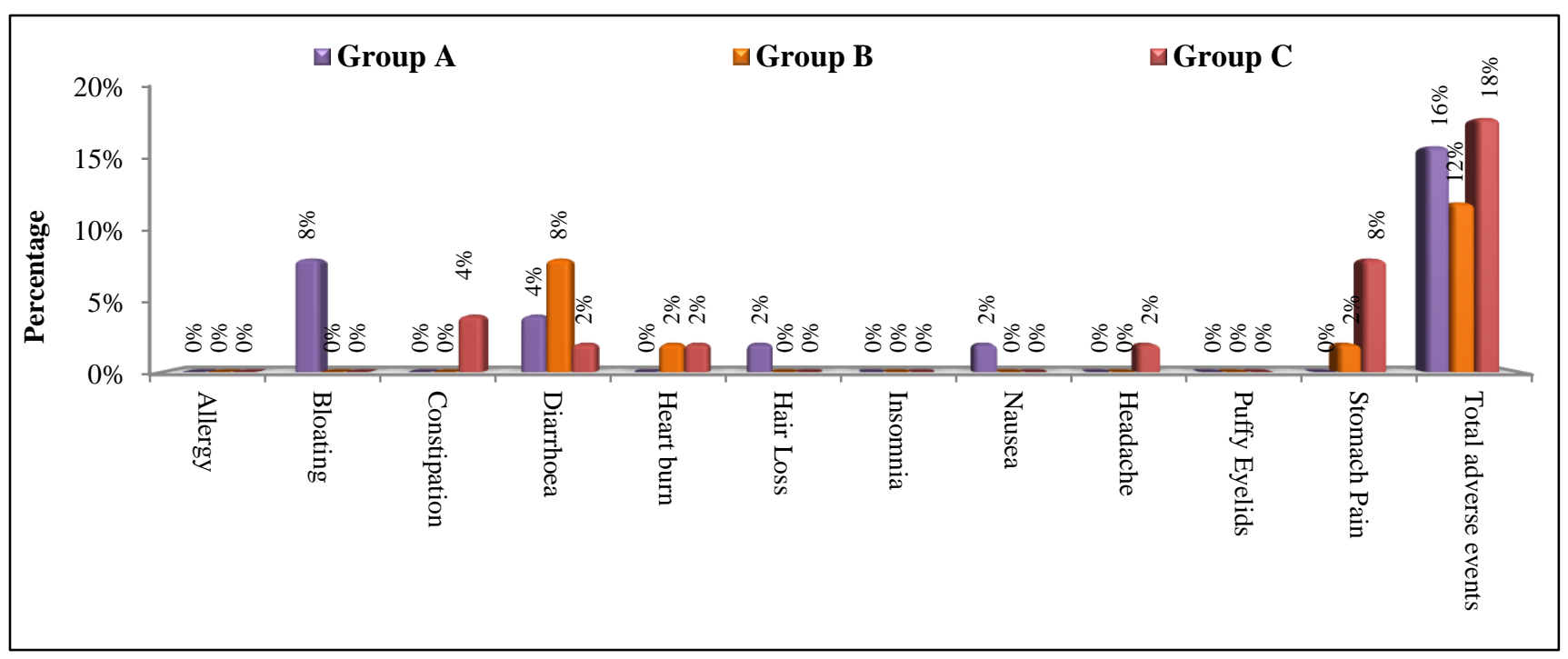

Figure 4: Comparison of adverse events between group A, group B and group C at last visit.

Table 1: Comparison of the demographic information of the patients with regard to age, gender and weight in all the three groups.

\begin{tabular}{|c|c|c|c|c|c|c|c|}
\hline \multirow{2}{*}{\multicolumn{2}{|c|}{ Demographic information }} & Group A & Group B & Group C & \multirow{2}{*}{$\begin{array}{l}\text { Group A- } \\
\text { Group B }\end{array}$} & \multirow{2}{*}{$\begin{array}{l}\text { Group A- } \\
\text { Group C }\end{array}$} & \multirow{2}{*}{$\begin{array}{l}\text { Group B- } \\
\text { Group C }\end{array}$} \\
\hline & & No. (\%) & No. (\%) & No. (\%) & & & \\
\hline \multirow{7}{*}{ Age (years) } & $35-45$ & $12(24 \%)$ & $14(28 \%)$ & $15(30 \%)$ & \multirow{7}{*}{0.199 (NS) } & \multirow{7}{*}{0.103 (NS) } & \multirow{7}{*}{0.706 (NS) } \\
\hline & $46-55$ & $23(46 \%)$ & $19(38 \%)$ & $20(40 \%)$ & & & \\
\hline & $56-65$ & $15(30 \%)$ & $17(34 \%)$ & $15(30 \%)$ & & & \\
\hline & Total & $50(100 \%)$ & $50(100 \%)$ & $50(100 \%)$ & & & \\
\hline & Range & $35-60$ & $36-60$ & $36-60$ & & & \\
\hline & Median & 55.00 & 50.00 & 49.00 & & & \\
\hline & Mean age & $52.12 \pm 7.69$ & $50.18 \pm 7.30$ & $49.62 \pm 7.52$ & & & \\
\hline \multirow{3}{*}{ Gender } & Male & $36(72 \%)$ & $36(72 \%)$ & $31(62 \%)$ & \multirow{3}{*}{0.449 (NS) } & \multirow{3}{*}{$0.071(\mathrm{NS})$} & \multirow{3}{*}{0.082 (NS) } \\
\hline & Female & $14(28 \%)$ & $14(28 \%)$ & $19(38 \%)$ & & & \\
\hline & Total & $50(100 \%)$ & $50(100 \%)$ & $50(100 \%)$ & & & \\
\hline \multirow{7}{*}{ Weight (kg) } & $51-60 \mathrm{~kg}$ & $20(40 \%)$ & $18(36 \%)$ & $21(42 \%)$ & \multirow{7}{*}{$0.354(\mathrm{NS})$} & \multirow{7}{*}{$0.566(\mathrm{NS})$} & \multirow{7}{*}{0.739 (NS) } \\
\hline & $61-70 \mathrm{~kg}$ & $25(50 \%)$ & $26(52 \%)$ & $21(42 \%)$ & & & \\
\hline & $>70 \mathrm{~kg}$ & $05(10 \%)$ & $06(12 \%)$ & $08(16 \%)$ & & & \\
\hline & Total & $50(100 \%)$ & $50(100 \%)$ & $50(100 \%)$ & & & \\
\hline & Range & $54-74$ & $56-70$ & $54-74$ & & & \\
\hline & Median & 62.00 & 63.00 & 62.00 & & & \\
\hline & Mean Age & $62.92 \pm 5.63$ & $63.96 \pm 5.54$ & $63.58 \pm 5.83$ & & & \\
\hline
\end{tabular}

Table 2: Comparison of distribution of the disease in left knee, right knee or both and the duration of disease in all the groups.

\begin{tabular}{|c|c|c|c|c|c|c|c|}
\hline \multirow{2}{*}{ Diagnosis } & & Group A & Group B & Group C & \multirow{2}{*}{$\begin{array}{l}\text { Group A- } \\
\text { Group B }\end{array}$} & \multirow{2}{*}{$\begin{array}{l}\text { Group A- } \\
\text { Group C }\end{array}$} & \multirow{2}{*}{$\begin{array}{l}\text { Group B- } \\
\text { Group C }\end{array}$} \\
\hline & & No. (\%) & No. (\%) & No. (\%) & & & \\
\hline \multirow{4}{*}{ Diagnosis } & Left knee & $17(34 \%)$ & $16(32 \%)$ & $15(30 \%)$ & \multirow{4}{*}{$\begin{array}{l}0.837 \\
(\mathrm{NS})\end{array}$} & \multirow{4}{*}{0.095 (NS) } & \multirow{4}{*}{0.117 (NS) } \\
\hline & Right knee & $19(38 \%)$ & $21(42 \%)$ & $19(38 \%)$ & & & \\
\hline & Both knees & $14(28 \%)$ & $13(26 \%)$ & $16(32 \%)$ & & & \\
\hline & Total & $50(100 \%)$ & $50(100 \%)$ & $50(100 \%)$ & & & \\
\hline \multirow{4}{*}{$\begin{array}{l}\text { Disease } \\
\text { duration }\end{array}$} & $<1$ year & $10(20 \%)$ & $12(24 \%)$ & $12(24 \%)$ & \multirow{4}{*}{$\begin{array}{l}0.124 \\
(\mathrm{NS})\end{array}$} & \multirow{4}{*}{$0.142(\mathrm{NS})$} & \multirow{4}{*}{$0.122(\mathrm{NS})$} \\
\hline & $1-2$ years & $22(42 \%)$ & $22(44 \%)$ & $20(40 \%)$ & & & \\
\hline & $>2$ years & $18(36 \%)$ & $16(32 \%)$ & $18(36 \%)$ & & & \\
\hline & Total & $50(100 \%)$ & $50(100 \%)$ & $50(100 \%)$ & & & \\
\hline
\end{tabular}


Table 3: Comparison of mean functional capacity scores between group A, group B, And group C at different visits.

\begin{tabular}{|lllllll|}
\hline Visit (duration) & Group & $\begin{array}{l}\text { Mean } \\
\text { difference }\end{array}$ & $\begin{array}{l}\text { Std. Error of } \\
\text { mean }\end{array}$ & t-test & p value & Sign. \\
\hline \multirow{3}{*}{ Baseline (0 week) } & A and B & $0.10 \pm 0.04$ & 0.10 & 0.959 & 0.340 & NS \\
\cline { 2 - 8 } & A and C & $0.18 \pm 0.02$ & 0.09 & 1.830 & 0.070 & NS \\
\hline \multirow{3}{*}{ Visit 1 (4 week) } & B and C & $0.08 \pm 0.06$ & 0.10 & 0.786 & 0.434 & NS \\
\hline \multirow{3}{*}{ Visit 2 (8 week) } & A and B & $0.08 \pm 0.11$ & 0.11 & 0.715 & 0.476 & NS \\
\hline & A and C & $-0.80 \pm 0.15$ & 0.11 & 7.353 & 0.001 & HS \\
\hline \multirow{3}{*}{ Visit 3 (12 week) } & B and C & $-0.88 \pm 0.04$ & 0.10 & 9.146 & 0.001 & HS \\
\hline & A and B & $0.18 \pm 0.19$ & 0.09 & 1.902 & 0.060 & NS \\
\hline & A and C & $-1.92 \pm 0.12$ & 0.10 & 19.068 & 0.001 & HS \\
\hline & B and C & $-2.10 \pm 0.07$ & 0.08 & 25.714 & 0.001 & HS \\
\hline
\end{tabular}

\section{DISCUSSION}

Osteoarthritis is a chronic disease that impairs quality of life and often this is associated with unsatisfactory control of symptoms. According to guidelines management of OA consists mostly of symptomatic treatment i.e. reduction of pain and improvement of joint function, which relies on the combination of non-pharmacologic and pharmacologic approaches. Non-pharmacological approaches include weight reduction, exercise, bracing and splinting to help support painful or unstable joint. ${ }^{3}$ Medical management is mostly palliative with NSAIDs being the mainstay of therapy.

The clinical trial GAIT which included 1500 patients was done by Clegg $\mathrm{D}$ et al, showed that combination of glucosamine and chondroitin sulphate, appeared to be effective in reducing pain intensity. ${ }^{10}$ In present study it was found that there was reduction in pain intensity, as the subsequent visits show a highly significant difference between group A (glucosamine and chondroitin sulphate) and group C (Placebo).

In present study it was found that reduction in pain intensity with rosehip as compared to placebo was highly significant. The first randomized controlled trial of rosehip done by Schwager J et al, involved 100 patients with painful, radio graphically verified osteoarthritis of the hip or knee.

These patients, some of whom were end stage and awaiting joint replacement, were randomized to receive either $2.5 \mathrm{~g}$ standardized rosehip powder or placebo twice daily for 4 months. Results showed that in comparison with placebo, rosehip powder significantly reduced pain $(\mathrm{p}=0.035)$ with $64.6 \%$ of patients receiving rosehip reporting at least some reduction of pain. Rosehip-treated patients also experienced improved hip flexion $(\mathrm{p}=0.033)$ with no significant change observed for internal and external rotation of the hips or knee flexion. ${ }^{11}$

Between the groups taking glucosamine plus chondroitin sulphate (group A) and rosehip (group B), there was highly significant reduction in pain intensity after 12 weeks of continuous administration of rosehip as compared to glucosamine and chontroitin sulphate. A study conducted by Christensen $\mathrm{R}$, showed similar results as far as reduction in pain intensity is concerned. ${ }^{12}$

In present study it was observed that there was highly significant reduction in swelling, joint tenderness and erythema in patients taking glucosamine plus chondrotin sulphate group A and rosehip (group B) as compared to placebo (group C). Similar results were found in study done by Warholm $\mathrm{O}$, that there was improvement in joint tenderness and joint mobility by rosehip. ${ }^{13,14}$

Between the groups taking glucosamine and chondroitin sulphate and rosehip there was non-significant difference in reduction of erythema and pain on movement while there was a significant reduction of joint tenderness in patients taking Rosehip.

In a placebo controlled, randomized, double blind crossover trial involving 94 patients done by Whinther KA, it was observed that there was significant improvement in functional capacity of patients taking rosehip. Similar results were observed in our study. ${ }^{15}$

A double blind, placebo controlled, crossover study involving 112 patients with osteoarthritis of the hip, knee, hand and neck was done by Rein $\mathrm{E}$ et al, and it was observed that rosehip causes improvement in overall assessment of the patients with osteoarthritis as compared with placebo. 
Similar results were observed in present study showing significant improvement in overall assessment of patients using rosehip compared to placebo. ${ }^{16}$ However some studies have shown that there is no significant benefit with the use of glucosamine and chondroitin sulphate in patients of osteoarthritis. ${ }^{17}$

\section{Safety}

Present study clearly showed that all the drugs used in were safe with minor adverse drug reactions and similar results were shown by a study which concluded that rosehip is extremely safe with occasional mild allergic reaction or gastrointestinal complaint but no serious adverse effects. ${ }^{18}$

\section{CONCLUSION}

It was therefore concluded from the results of the present study, that both glucosamine and chondroitin sulphate and Rosehip were effective in patients of OA knee, with each drug showing significant improvement in all efficacy parameters throughout the study compared to placebo. Both the drugs were well tolerated and systemically safe as none of the study participants discontinued drug treatment during the entire study period.

It was also concluded that rosehip is superior in efficacy to glucosamiune and chondroitin sulphate in reducing pain, joint tenderness, swelling, functional capacity and overall assessment especially when continuously administered for 3 months. Further studies with larger sample size are required for drawing more valuable results.

\section{ACKNOWLEDGEMENTS}

Authors would like to thank Dr. Anjleen Kaur, Dr. Prabhsimran Singh and Dr. Amandeep Singh for their fruitful discussion which initiated this research.

\section{Funding: No funding sources}

Conflict of interest: None declared

Ethical approval: The study was approved by the Institutional Ethics Committee

\section{REFERENCES}

1. Woolf AD, Pfleger B. Burden of major musculoskeletal conditions. Bull World Health Organization. 2003;81:646-56.

2. Dieppe PA, Lohmander LS. Pathogenesis and management of pain in osteoarthritis. Lancet. 2005 Mar 12;365(9463):965-73.

3. Brandt KD. Osteoarthritis In: Kasper DL, Fauci AS, Longo DL, Braunwald E, Hauser SL, Jameson JL, eds. Harrison's Principles of Internal Medicine. 16th ed. Newyork, NY:Mcgraw-Hill companies; 2005:2037.

4. Lippiello L. Glucosamine and chondroitin sulfate: biological response modifiers of chondrocytes under simulated conditions of joint stress. Osteoarthr Cartilage. 2003 May 1;11(5):335-42.
5. Christensen LP. Galactolipids as potential health promoting compounds in vegetable foods. Recent Patents Food Nutr Agricult. 2009 Jan 1;1(1):50-8.

6. Wenzig EM, Widowitz U, Kunert O, Chrubasik S, Bucar F, Knauder E, et al. Phytochemical composition and in vitro pharmacological activity of two rose hip (Rosa canina L.) preparations. Phytomedicine. 2008 Oct 17;15(10):826-35.

7. Spilker B. Drug development and approval process. In: Speight TM, Holford NHG, eds. Avery's Drug Treatment. 4th ed. Auckland Adis International; 1997:423-449.

8. Allen IE, Seaman CA. Likert scales and data analyses. Quality Progress. 2007 Jul 1;40(7):64-5.

9. Crossland J. Statistics in pharmacology. In: Lewis's pharmacology. 5th ed. Edinburg: Churchill Livingstone; 1982:112-114.

10. Clegg DO, Reda DJ, Harris CL, Klein MA, O'dell JR, Hooper MM, et al. Glucosamine, chondroitin sulfate, and the two in combination for painful knee osteoarthritis. N Eng J Med. 2006 Feb 23;354(8):795808 .

11. Schwager J, Hoeller U, Wolfram S, Richard N. Rose hip and its constituent galactolipids confer cartilage protection by modulating cytokine, and chemokine expression. BMC Complement Altern Med. 2011 Dec;11(1):105.

12. Christensen R, Bartels EM, Bliddal H. 521 Efficacy of glucosamine hydrochloride or specialized rosehip powder in osteoarthritis patients: an indirect comparison meta-analysis. Osteoarthritis Cartilage. 2009 Sep 1;17:S279.

13. Warholm O, Skaar S, Hedman E, Mølmen HM, Eik L. The effects of a standardized herbal remedy made from a subtype of Rosa canina in patients with osteoarthritis: a double-blind, randomized, placebocontrolled clinical trial. Cur Therap Res. 2003 Jan $1 ; 64(1): 21-31$.

14. Chan PS, Caron JP, Rosa GJ, Orth MW. Glucosamine and chondroitin sulfate regulate gene expression and synthesis of nitric oxide and prostaglandin E2 in articular cartilage explants. Osteoarthritis Cartilage. 2005 May 1;13(5):387-94.

15. Winther K, Apel K, Thamsborg G. A powder made from seeds and shells of a rose-hip subspecies (Rosa canina) reduces symptoms of knee and hip osteoarthritis: a randomized, double-blind, placebocontrolled clinical trial. Scand J Rheumatol. 2005 Jan $1 ; 34(4): 302-8$.

16. Rein E, Kharazmi A, Winther K. A herbal remedy, Hyben Vital (stand. powder of a subspecies of Rosa canina fruits), reduces pain and improves general wellbeing in patients with osteoarthritis:a doubleblind, placebo-controlled, randomised trial. Phytomedicine. 2004 Jul 20;11(5):383-91.

17. Yang S, Eaton CB, McAlindon TE, Lapane KL. Effects of glucosamine and chondroitin on treating knee osteoarthritis: An analysis with marginal structural models. Arthritis Rheumatol. 2015 Mar;67(3):714-23. 
18. Chrubasik S, Chrubasik C, Neumann E, MüllerLadner U. For anti-inflammatory efficacy of rosehip powder. J Phytotherapy. 2009 Oct;30(05):227-31.
Cite this article as: Kaur K, Kaur A, Singh P, Bakshi AS. A comparative study of efficacy and safety of glucosamine plus chondroitin sulphate versus rosehip as add on therapy to NSAIDs in patients suffering from osteoarthritis. Int J Basic Clin Pharmacol 2018;7:2254-60. 